\title{
Identidades étnicas en Tarapacá a inicios del siglo $\mathrm{XXI}^{1}$
}

\author{
VIVIAN GAVILÁN \\ Centro de Investigaciones del Hombre del Desierto (CIHDE) \\ Universidad Arturo Prat. Iquique. Chile
}

\section{RESUMEN}

Este artículo expone resultados de una investigación acerca de los procesos de configuración de las identidades étnicas en la región de Tarapacá, norte de Chile. Presenta la hipótesis de que la población de origen indígena ha intentado quitarse el estigma de "indio" utilizando elementos de la modernidad para reafirmar su identidad étnica. Por encima de otras identidades, recurren a la etnicidad como paradigma para buscar inclusión en un sistema históricamente excluyente. Esta identidad estratégica se apoya en una identidad emblemática que marca las fronteras con el q'ara, categoría clasificatoria aymara del "otro; aquel que no desciende del 'Inca'". Símbolo que representa el pasado, un espacio-tiempo mítico, un sistema normativo y de valores que proporciona un esquema de percepción para orientar las prácticas del presente. Pero este proceso es conflictivo y heterogéneo, ya que se trata de un grupo social diverso en términos de clase, género y grado de aculturación.

Palabras clave: Identidades étnicas, Pueblos indígenas, Etnicidad, Norte de Chile.

\section{SUMMARY}

The author has done research on the processes of formation of ethnic identities in the region of Tarapacá, in northern Chile. She argues that the indigenous people in Tarapacá have recently tried to shake off the stigma of "Indianness" by using elements of modernity in asserting their ethnic identity. Beyond other signs for identity-building, they have resorted to ethnicity as they strive to be included in a historically excluding system. This strategy depends upon defining and reproducing the symbolic borders with the q'ara, the Aymara category for the "other": he or she who does not descend from the "Inca." For them the "Inca" represents the past, a mythical space-time and a system of norms and values that serves as a

\footnotetext{
${ }^{1}$ Este trabajo forma parte de los resultados de investigación de los proyectos Fondecyt № 1020507 y 1050143.
}

RDTP, LX, 2 (2005): 77-102 
guide for the practices of the present. Yet this process is conflictive and heterogeneous, since this indigenous people are diverse in terms of class, gender and degree of acculturation.

Key words: Social Identities, Ethnicity, Indigenous People, Northern Chile.

Los hombres bacen su propia bistoria, pero no la hacen a su libre arbitrio, bajo circunstancias elegidas por ellos mismos, sino bajo aquellas circunstancias con las que se encuentran directamente, que existen y les han sido legadas por el pasado. La tradición de todas las generaciones muertas oprime como una pesadilla el cerebro de los vivos. Y cuando éstos aparentan dedicarse precisamente a transformarse y a transformar las cosas, a crear algo nunca visto, en estas épocas de crisis revolucionaria es precisamente cuando conjuran temerosos en su auxilio los espiritus del pasado, toman prestados sus nombres, sus consignas de guerra, su ropaje, para, con este disfraz de vejez venerable y este lenguaje prestado, representar la nueva escena de la bistoria universal.

Karl Marx, El Dieciocho Brumario de Luis Bonaparte

\section{INTRODUCCIÓN}

El propósito de este artículo es reflexionar sobre las identidades étnicas en la región de Tarapacá, en el norte de Chile. Intenta observar los procesos de afirmación étnica hoy, a partir del análisis de la visión del actor social indígena.

El espacio territorial que aquí nos ocupa, es una de las regiones administrativas del Estado de Chile que cobija a una población de habla aymara, segundo grupo étnico numéricamente más importante del país². Situada en la zona meridional de los Andes, es una región en la que han interactuado múltiples grupos étnicos-nacionales, varios provenientes de Asia y Europa, y principalmente una población de tres naciones: Chile, Perú y Bolivia, dada su condición de frontera. Considerada como la más

${ }^{2}$ El censo del 2002 registra un total de 40.934 personas aymaras, de las cuales 20.607 son mujeres y 20.327 son hombres. Cifra que asciende a 48.501 a nivel nacional. A diferencia de 1992, censo anterior que registró a las personas que se identificaban como mapuche, aymara o rapa nui, el último consultó la pertenencia a alguno de los ocho grupos indígenas reconocidos por la ley vigente: Mapuche, Aymara, Rapa Nui, Colla, Quechua, Atacameños, Yamana y Alacalufe (Características sociales y culturales Síntesis de resultados INE). 
desértica del mundo, registra 10.000 años de historia. Diferentes colectividades humanas habitaron la costa, valles y altiplano, aprovechando los recursos marinos, los escasos recursos hídricos para la explotación agrícola y ganadera y sus abundantes minerales. Son entonces sus descendientes, o aquellos que hoy asumen serlo, nuestro foco de interés.

La población indígena que dice pertenecer a la etnia aymara se encuentra principalmente en los espacios urbanos, aunque una fracción de la misma sigue vinculada al campo como parte de su estrategia de supervivencia o de vida ${ }^{3}$. Su inserción en las ciudades en las últimas décadas se expresa en una expansión de hogares residentes en barrios populares de las dos principales ciudades costeras: Arica e Iquique. Las familias conviven con otras, originarias o de segundas, terceras y cuartas generaciones de unidades provenientes de otras zonas geográficas del país (norte chico, zona centro y sur) y de los países fronterizos; muchas de las cuales han emigrado de las oficinas salitreras ${ }^{4}$ hoy abandonadas. Una de las características de estos grupos domésticos es su marcado arechazo a lo indígena", tanto racial como cultural. Asimismo, las familias de origen indígena no se integran fácilmente a las actividades barriales, debido a decisiones personales y argumentos laborales. Existe la tendencia a no interesarse por los propósitos de las organizaciones vecinales, lo que es visto por sus dirigentes como apatía y desinterés por el bien común. En la práctica se observan, tanto en uno como en otro grupo, argumentaciones para la no integración en el ámbito local. Alcanzar mayores niveles de escolaridad y algún oficio o profesión constituye un ideal bastante generalizado, pero, la socialización escolar, claramente orientada a homogenizar culturalmente a los futuro/as ciudadano/as y con marcados sesgos discriminatorios hacia lo indígena, acarrea conflictos entre generaciones en el interior del hogar y la familia respecto de las calificaciones en las formas de vida cotidiana, respecto de las prácticas religiosas y respecto de las relaciones entre hombres y mujeres.

En este sentido, las organizaciones que reivindican derechos étnicos

\footnotetext{
${ }^{3}$ Según los datos censales la población indígena a nivel nacional se ocupa mayoritariamente en la agricultura. Esto se debe a la mayor proporción de población mapuche, puesto que los demás pueblos se ocupan mayoritariamente en el comercio. Los hombres aymara, sin embargo, se ocupan mayoritariamente en Agricultura: 24,8\%. Las mujeres, a nivel nacional, se ubican en la rama de Hogares Privados con servicio doméstico: $32,4 \%$. Entre los aymara sin embargo, la población femenina se ocupa principalmente en el comercio con el: 30,1\% (Informe MIDEPLAN, "Catorce años de Política Indígena http://www.mideplan.cl/publico/seccion.php?secid=2).

${ }^{4}$ Nombre que recibían los campamentos mineros en la época de la industria del
} salitre. 
han cumplido un papel central al declarar por primera vez cierta resistencia al sistema escolar, al rechazo cultural en los barrios y en la valoración de la tradición andina. A lo cual habría que agregar la apropiación de contenidos ofrecidos por el sistema escolar, por los medios de comunicación, ONGs, iglesias y, en especial, por las políticas gubernamentales de reconocimiento y afirmación positiva que estarían incidiendo en nuevas formas de interacción.

El estudio de la población de origen indígena en la región norte de Chile ha tendido a no considerar los procesos históricos de los cuales forman parte; por lo tanto, cierta visión esencialista de la cultura ha estado presente en la discusión. Asimismo, y como ha señalado G. Giménez para México (2000: 59), se observan pocas investigaciones empíricas acerca de las representaciones culturales que tienen de sí mismos en contraposición con la cultura mestiza nacional. Si asumimos que la identidad étnica requiere como punto de apoyo "una matriz cultural" que es finalmente subjetiva, contrastada e históricamente situada, es importante conocer los componentes de estas representaciones.

¿A partir de qué argumentos se construye la identidad étnica? El análisis de los mismos puede contribuir a comprender mejor los procesos particulares que vive la población indígena que hoy forma parte de Chile, un estado-nación que presenta menor flexibilidad jurídica que otros países latinoamericanos. En este contexto, planteo como hipótesis que el estigma impuesto al "indio" ha dado lugar a identidades estigmatizadas y que, como una forma de desembarazarse de éste, los actores utilizan elementos de la modernidad. Recurren a la etnicidad como paradigma, por encima de otras identidades, para buscar su inclusión en un sistema históricamente excluyente. Cuando la etnicidad es útil para reclamar exclusión de un sistema político y de una sociedad que discriminan negativamente su cultura, ser indígena constituye una alternativa para reivindicar el derecho a la diferencia cultural y para acceder a los recursos del Estado. Este proceso es conflictivo y heterogéneo, ya que se trata de un grupo social diverso en términos de clase, género y grado de aculturación.

\section{ALGUNAS ACLARACIONES CONCEPTUALES: IDENTIDAD, CULTURA Y ACULTURACIÓN}

La revisión que se ha realizado de estos conceptos en los últimos años nos proprociona herramientas de gran utilidad para comprender y explicar las dinámicas socioculturales en América Latina. La perspectiva teórica que intento seguir aquí es aquella que sostiene una visión dinámica de la cultura, entendida, por tanto, como un producto histórico. Una construcción que se inscribe en la historia de las relaciones de los grupos 
sociales entre sí y que en consecuencia no existe independientemente de éstas, que son siempre relaciones desiguales (Cuche 2000: 86).

Identidad social se refiere a la autopercepción de un nosotros relativamente homogéneo en contraposición con los otros, con base a atributos, marcas o rasgos distintivos subjetivamente seleccionados y valorizados; que a la vez funcionan como símbolos que delimitan el espacio de la mismidad identitaria. La identidad étnica es una especificación de la identidad social y consiste en la autopercepción subjetiva que tienen de sí mismos los actores llamados "grupos étnicos" (Giménez 1994: 170).

Como señala D'Andrea (2000) la especificidad de una agrupación social étnica estaría dada por un tipo de pertenencia que se funda, en última instancia, en la representación subjetiva de un vínculo de parentesco; aquel que, a partir de las semejanzas más variadas entre los miembros del grupo mismo, cree en la descendencia de antepasados comunes y se delimita con respecto a los demás grupos en virtud de la representación de un vínculo de sangre, por la convicción de un origen común. Agrega que su eficacia como aglutinante del grupo social no depende de su valor de verdad, sino de argumentos que se basan en todas las semejanzas que atestiguan un pasado compartido: rasgos somáticos, lengua, cultura y tradiciones compartidas, religión, mitos y memorias, usos y costumbres. Sin embargo, el grupo étnico no constituye un grupo cultural, lingüístico o religioso. Se requiere que estos componentes se construyan como argumentos. A través de la percepción del parentesco se construyen fronteras, las que en virtud de la representación de una consanguinidad han sido trazadas entre los que están afuera y los que están dentro del grupo social (ibid).

Por otra parte, aclararnos qué entenderemos por proceso de aculturación es clave para comprender los cambios que se producen en la cultura. Cuche nos dice que los procesos de aculturación son un fenómeno universal, aún cuando se de en formas y grados muy diversos. El proceso de cada cultura en situación de contacto cultural; es decir, de desestructuración, deconstrucción y luego de reestructuración es, en realidad, el principio de evolución de cualquier sistema cultural. Toda cultura está en un permanente proceso de construcción, desestructuración y reconstrucción. Lo que varía es la importancia de cada fase según las situaciones. De acuerdo con este autor, habría que tener presente que todo conjunto cultural tiende hacia la coherencia y cierta autonomía simbólica que le confiere su carácter original singular y que es posible analizar un rasgo cultural independientemente del sistema cultural al que pertenece. Esto remite a estudiar toda cultura sin a priori, sin compararla y mucho menos medirla prematuramente según otras culturas; privilegiar 
el enfoque compresivo, en definitiva, hipotetizar que, incluso en el caso de las culturas dominadas, una cultura siempre funciona como una cultura, nunca es totalmente dependiente, nunca es totalmente autónoma (Cuche 2002: 76).

Giménez (1994: 172) sugiere que la relación entre identidad, cultura y aculturación permite entender los procesos de modernización en América Latina. Postula que la identidad requiere siempre, como punto de apoyo, una "matriz cultural" portadora de los emblemas de contraste que marcan sus límites; pero esa matriz no se identifica con la cultura objetivada observable desde el exterior, sino con la cultura subjetivada resultante de la internalización selectiva de algunos elementos de la cultura institucionalmente preconstruida. De esta manera, tomando en cuenta las diferentes modalidades del cambio de identidad, el autor sostiene que si se asume una perspectiva diacrónica, la identidad se define en primer lugar por la continuidad de sus límites; es decir por sus diferencias y no tanto por el contenido cultural que en un momento determinado marca simbólicamente dichos límites o diferencias. Esta tesis lleva a pensar que la modernización por aculturación no implica por sí misma una mutación de identidad, sino solo su redefinición adaptativa. Incluso puede provocar la reactivación de la identidad mediante procesos de exaltación regenerativa (ibid:: 174).

\section{LOS AYMARA UN GRUPO ÉTNICO}

Los aymara constituyen un grupo étnico pues se trata de una colectividad culturalmente distinguible, tanto por la población no indígena como también por ellos mismos. La sociedad regional identifica a la población de ascendencia indígena como un todo, a través de rasgos como la lengua, la religión, la organización social, y la raza (fenotipo) $)^{5}$. La semejanza de estos atributos con los de la población indígena de los países vecinos (Perú y Bolivia) ha permitido la asimilación de este pueblo como un segmento extranjero. Pero también opera una clasificatoria social que se asienta en supuestas diferencias biológicas, cuya valoración es claramente despreciativa.

\footnotetext{
${ }^{5}$ La clasificación de los pueblos indígenas en la región como un bloque conlleva la dificultad para comprender las diferenciaciones internas y tiene que ver con la falta de voluntad de parte de la población no indígena por reconocer la visión de los propios actores sociales. Durante la colonia la categoría social Indio atomizó a una diversidad de grupos. En la conquista temprana los cronistas señalan que a las etnias no se les otorgaba un gentilicio que las abarcara, sino que se les denominaba por el nombre del valle o del cacique principal (Hidalgo 2004: 25).
} 
Los trabajos que abordan la cuestión de la cultura y los procesos de identidad étnica en la región han realizado grandes aportes para la comprensión de la realidad social del presente en el norte chileno ${ }^{6}$. En general, podríamos señalar que la sociedad y la cultura aymara se conciben como dependientes de los procesos sociales impulsados por el sistema colonial, por el Estado y la sociedad nacional, siendo permanentemente socavadas. Una línea de interpretación postula la desestructuración de la comunidad indígena. Para éstos, los procesos de aculturación impuestos llevarían a la pérdida de la identidad aymara, pues se antepone la identificación con la nación peruana, primero y con posterioridad con la chilena, motivando y acelerando el proceso de emigración a la ciudad y el abandono de la tradición. En este sentido los procesos de modernización son los causantes de la pérdida cultural.

J. van Kessel afirma, sin embargo que a pesar de ello la identidad étnica ya no aparece tan despreciada y puede ser provechosa:

\begin{abstract}
...el peligro y la angustia de perderla parecen despertar un movimiento renacentista entre los propios aymaras. Prueba de ello son las nuevas organizaciones que nacieron en el campo y la ciudad. Otros indicios del mismo proceso son por ejemplo la participación aymara en el proceso de la nueva ley indígena. Podría argumentarse que por la política gubernamental y la acción de la sociedad circundante, la comunidad aymara y sus estructuras sociales fueron definitivamente desmanteladas sin embargo, no estamos frente a una nivelación acabada ni a la chilenización pura y simple, sino frente a múltiples brotes de un fenómeno de reetnificación de los aymaras de Chile (Kessel 1996: 67).
\end{abstract}

El autor no se pregunta por qué esta posible identidad estratégica se elabora en determinado contexto. No cabe esta pregunta en una visión que postula la continuidad de una identidad étnica fundamental y de larga duración, a pesar de las transformaciones. Supone así una especie de alteridad no contaminada, se representa una sociedad y cultura indígena con un pasado o un antes virtual. Se tiende a olvidar la permanente relación de intercambios culturales que se han producido a través de la historia y la posición subordinada de las comunidades de origen indígena; se olvida que nos situamos en un contexto de larga tradición colonialista en el cual las personas no han.sido un ente pasivo, sino sujetos activos de los procesos sociales. Esta visión del problema indígena en Tarapacá tiende a un pensamiento dicotómico que opone "lo andino" a occidente, como si la población no hubiese participado de los procesos regionales

\footnotetext{
${ }^{6}$ Martínez (1976, 1989); Cereceda (1978); Grebe (1986); Kessel (1990-91); Chipana (1986); González y Gavilán (1989); Tudela (1992, 2003); Guerrero (1993, 1996); Gundermann (2000, 2002).
} 
que de hecho provocaron cambios culturales. Pero la continuidad y discontinuidad cultural es una cuestión que hay que investigar.

Otra interpretación, desde una visión más constructivista, plantea que la cultura aymara ha ido transformándose a través de los distintos contextos de dominación social y política, sin que ello implique necesariamente desintegración. A finales de los ochenta, después de varios años trabajando con comunidades campesinas y dirigentes urbanos, reflexionamos sobre la cuestión de la identidad entre los aymara7. Veíamos entonces, que no existía un término propio que los identificara como un todo frente a los extranjeros o los otros. No disponen, por ejemplo, de un genérico como mapuche. Las familias del altiplano a finales de los setenta utilizaban el término aymarista para referirse al manejo de la lengua (Jaqui Aru). Se autoidentificaban de acuerdo a la localidad o pueblo entre ellos mismos y cuando interactuaban con un no indígena se autoclasificaban como "del interior" y posteriormente (inicios de los ochenta) con el nombre de los nacientes municipios, nuevas unidades político-administrativas inventadas por el estado chileno en tiempos de dictadura. Así, aunque constatábamos la tendencia a una identidad localista, no se sabía mucho acerca de su emergencia y explicación.

Planteamos, entonces, que para los aymaras chilenos la noción de grupo étnico pareciera ser una categoría vacía, dado que sus intereses se realizan en la pequeña localidad de origen. Sin embargo, ese espacio había sido copado por la mirada o definición que proporciona la sociedad regional que sí los abarca como un sistema étnico contrastante. En este sentido, para ellos la noción de grupo étnico, la posibilidad de pensarse como un todo y de asumir una identidad étnica parecía precisamente provenir de asumir la posición discriminada y estigmatizante que le ofrece el otro: la población no indígena.

Entre los elementos que identificábamos como factores de cohesión local se hallaban el sistema parental, que incidía en la circulación de los recursos y organizaba también los matrimonios; la aprobación o el manejo de ciertos recursos y de la fuerza de trabajo; las reuniones comunales ("Asamblea"), cuyo funcionamiento y estructura particular supone la necesidad de alcanzar decisiones consensuadas y una rotación permanente de los cargos entre todos sus componentes; la religiosidad y las expresiones rituales (González y Gavilán 1992). Hoy podría decirse que una de las limitaciones de estas conclusiones fue no recuperar la visión de sí mismos en relación a la población no indígena. Es decir, consideramos sólo

\footnotetext{
${ }^{7}$ Me refiero a un grupo de profesionales que trabajábamos en un ONG en tiempos de dictadura. De aquí salió el trabajo al que se alude: Cultura e identidad étnica.
} 
aquellos factores que a la vista del etnólogo parecían funcionar como elementos de cohesión; y no la visión de los significados que los propios actores otorgan a esa identidad local. Héctor González (1997-2000) ha propuesto que a pesar de los procesos de aculturación los aymaras continúan diferenciándose culturalmente en la región y el país:

\begin{abstract}
Las transformaciones de pérdida y adopción de patrones y elementos culturales se relacionan con los conceptos de nacionalismo y globalización. Los aymaras de esta área han debido acomodarse a una nueva nacionalidad para pasar de peruanos a chilenos. La cultura de los aymara, bajo la égida chilena y en un contexto de ocupación pasa a ser el símbolo de la extranjeridad sometida y del atraso o barbarie (india) de los vencidos. El proyecto chilenizador habría significado el desencadenamiento de un proceso de perdida cultural y aculturación por imposición e imitación. Pese a los procesos reseñados, los aymaras continúan siendo un grupo particular y contrastante al interior de la región. Su cultura se ha transformado, pero mantiene espacios que aseguran su reproducción y le permiten la vitalidad suficiente como para asegurarles especificidad, incluso en sitios tan adversos como la ciudad (González 2000: 285).
\end{abstract}

H. Gundermann por su parte, a través de una exhaustiva investigación acerca de la emergencia de la comunidad histórica en el norte chileno, acaba por concluir que esta es producto de los procesos coloniales y de la instauración de una modernidad latinoamericana. Para él la persistencia debe verse como la continuidad transformada de las instituciones comunitarias andinas (Gundermann 2001a). Plantea que la continuidad debemos situarla en el plano de las representaciones más que formaciones discursivas auténticas, como tradiciones formales o seudotradiciones; y a nivel social las prácticas y sociabilidades tradicionales apoyarían la incorporación aymara a las corrientes regionales de la modernidad:

Los sistemas de relaciones con base en la localidad y el parentesco sirven a la migración y a las redes sociales construidas alrededor de la producción para el mercado, el transporte, el comercio agrícola y abastos y la economía informal de la nueva sociedad aymara (Gundermann 2001b: 22).

Postula, además, que la condición de indio o indígena sería el antecedente histórico más importante para comprender la identidad colectiva de hoy. El sistema de dominación colonial habría disuelto las identidades étnicas prehispánicas e instaurado dos nuevos tipos de identidad colectiva: a) la identidad local, que se construye en la realidad residencial y sociodemográfica de la llamada república de indio; b) otra más amplia: la identidad de indio; un estrato, una categoría social particular, sujeta a relaciones de dominación. Esta no sería una identidad étnica, porque resulta de una fusión de un conjunto de realidades socioculturales discretas, distinguibles y que se reconocían como especificas, como diferentes 
en tiempos precolombinos. Pero también es premoderna, tampoco es algo equivalente a una nación. Sería un tipo de identidad colectiva, es un tipo de pertenencia social y también un tipo de subjetividad asociada a esa pertenencia social que es impuesta, que se forma en los siglos coloniales teniendo como un elemento fundamental una relación colonial de dominación:

Quienes asimilan para el caso de los pueblos andinos, la condición de indio colonial y republicana temprana con la idea de etnia o de identidad étnica, considero que cometen un error, hay allí un abuso de los términos. Distinto es que las actuales identidades e identificaciones étnicas se formen entre otras cosas a partir de materiales históricos y de memorias que tienen que ver con la condición de indio colonial y también de la condición de indios republicanos tempranos. Pero no son una misma cosa (Gundermann 2004: 8-9).

A pesar de su declaración por asumir una concepción de identidades sociales que recupere al actor en la dimensión de su voluntad por distinguirse de otro, y de entender la identidad étnica como aquella que refiere a características culturales, y por tanto no siempre objetiva, parece no seguirlas en sus conclusiones. Si consideramos que el hecho empírico es que cualquier individuo o colectividad tiene varias identidades, y que estas identidades se hacen visibles y cobran importancia en determinados contextos (Oommen 1994), no se podría sostener que el sistema colonial disolvió las identidades étnicas prehispánicas. Al menos habría que investigar las diferentes modalidades del cambio de identidad y cómo las diferencias que los actores fueron elaborando subjetivamente sirvieron de base para establecer las pertenencias. La persistencia de la identidad local y la referencia a una comunidad de adscripción que refiere al "indio" se erigen sobre un sustrato cultural que es preciso investigar empíricamente. No se puede presuponer la existencia de identidades colectivas por el simple hecho de que los individuos pertenezcan a una categoría social.

La intervención del poder en los procesos identitarios es evidente, pero la imposición no implicó la eliminación de los límites étnicos. Los emblemas de contraste utilizados por esta población para marcar las fronteras son hoy un resultado de luchas sociales coloniales y neocoloniales, pero son éstos difícilmente observables desde el exterior. Sólo pueden conocerse observando cómo se han ido internalizando selectivamente algunos elementos de su cultura. La clasificación del "otro" por parte del "indio" nos remite a una continuidad de las fronteras étnicas durante varios siglos. Aunque las identidades se han ido transformando, el "indio" ha mantenido los límites que ellos definen como centrales. Aquello qu mamos identidad étnica siempre existió, aunque haya permanecido eclipsada por otras identidades como la nacional, la de campesino, etc. Y son los argu- 
mentos que elaboran los actores sociales para mantener estas fronteras los que facilitan seguir el paradigma étnico, sobrepasar la identidad local, de clase o de género en un contexto sociopolítico en que la diversidad cultural y la etnicidad emergen, cuestionando el sistema político en América Latina.

LA FRONTERA ÉTNICA: EL INDIO Y EL Q'ARA

La población indígena ha sido conformada como un grupo étnico (minoritario y marginalizado) en el territorio que ocupaba por otra colectividad dominante y que hasta hace poco se negaba a reconocer o desvirtuaba sus vínculos morales y simbólicos con dicho territorio. El Estado chileno condicionó su ciudadanía a su lealtad por la nación. Esto no implicó necesariamente renunciar a su lealtad étnica, sino que, dadas las condiciones socioeconómicas y sociopolíticas, la identidad nacional tuvo que ser relevada. Salir de la condición de indio a través del progreso fue la consigna para romper con el estigma.

Las diferencias culturales de la población regional son un dato de la realidad. Si bien la distinción con la cultura "india" ha sido históricamente establecida por la población mestiza a partir de un proyecto civilizatorio que consideró como cultura dominante la de la clase dominante, nos interesa revisar aquí cómo la población que hoy reivindica derechos étnicos pudo reconocer la diferencia cultural como estrategia política y cuáles son los argumentos que ella misma establece para elaborar esta diferencia.

Los aymara utilizan el término Q'ara para referirse al no indígena. Podríamos decir que esta expresión lingüística y sus connotaciones nos remite a cómo el "indio" clasifica al "otro". Aquél que, según su creencia, no desciende de sus antepasados; aquéllos que legaron una forma de vida, normas y valores, y el territorio.

Q'ara, en el diccionario de Bertonio aparece así:

dícese de todo lo que es pelado, como la cabeza, cerros, llanos y si es piedra o peña Hanccara:

Kara Ppekeñani; Calvo

Karalaccampu; cielo raso

Karaisi: vestido sin pelo

Karakbatatha: estar sin gente la plaza

Kara, de un solo color

Kara puntas de rostro blanco

(Bertonio, 1984: 47).

Asimismo la expresión karakhatha significa pelarse, quedar sin nada (ibid.: 357). ¿Por qué fue éste y no otro el término seleccionado? Esta 
pregunta es importante aquí no por su respuesta, sino por lo que implica en términos de background cultural. Como toda expresión lingüística, sus significados han variado a través del tiempo, el seguimiento de esta evolución es importante pues constituye un dato relevante para rescatar precisamente esos significados.

C. Chipana nos dice que en la actualidad Q'ara es el término que designa a una persona no india, ladino, blanco, refinado, ajeno a los andinos condición de extraño o ignorante en la cultura aymara (Chipana 1986: 256). Indica que Q'arakiptaña es la forma verbal que se usa para referirse a aquel que quiere imitar al Q'ara. Es interesante también reconocer otra derivación de esta raíz, como es la palabra Q'araxtaña que significa empobrecerse, pero no en el sentido de bienes materiales sino de cultura: de normas y valores. Justamente el término Q'ara significa pelado en el sentido de sin nada, que no tiene parientes. Q'ara no es precisamente extraño o extranjero, pues esta idea se expresa en la palabra Maysa Jaqui'. Rivière (1991) nos dice que en Bolivia la categoría lik'ichiri o kharisiri denomina un personaje del imaginario indígena que contiene elementos de representación del "otro". Es decir, del extranjero al mundo indio (un cura o un monje) que para cometer su fechoría se aprovecha del sueño de sus víctimas haciéndolas dormir, hipnotizándolas con la mirada, con la voz, el sonido de su campanilla o diversos ingredientes mágicos; con el objeto de extraer la grasa y no la sangre del cuerpo. Es decir, la fuerza vital del individuo. La relación que establece con la humanidad es vertical y desigual. Se describe como la antinomia del jilaqata; i. e. se niega a someterse a las normas, constituyendo de esta manera una amenaza para el grupo. Es rechazado por su origen étnico forastero y de su pertenencia al mundo de los "blancos" (sacerdote, agrónomo, ingeniero, etc.), distinguido de entrada como "otro" y explotador, ya sea porque, aunque originarios de la comunidad la han traicionado al no someterse a las obligaciones colectivas. Sea cual fuere el origen étnico de los lik'ichiri/kharisiri, es significativo que sean designados con dos términos: q'ara y wirakocha. Este último se usa para referirse y dirigirse a alguien, significa señor y es utilizado para designar a todo individuo cuyo estatus y poder son considerados como superiores.

\footnotetext{
${ }^{8}$ Referencias proporcionadas por el Profesor de Lengua Aymara, Elías Ticona.

${ }^{9}$ Esta información ha sido discutida con Elías Ticona, profesor del Instituto Isluga de la Universidad Arturo Prat. El término extranjero, ha sido tomado del Diccionario Aru Pirwa de Pedro García, que registra la lengua de la provincia de Iquique. En el Diccionario de L. Bertonio aparece la expresión Wasa para designar Extraño, desconocido o solterón y Wasa Jaque para extranjero o persona de otro país o nación.
} 
No se conoce, hasta ahora, ningún material etnográfico de esta naturaleza en Tarapacá; no obstante, las características de este personaje se relacionan directamente con las representaciones del no indígena. Así como la categoría "indio" contiene la carga de un estigma y subsume etnia y raza, Q'ara tiende a contener ciertos aspectos negativos, que resumen también ambas dimensiones. Esto aparece con mayor claridad en las elites indígenas que, para enfrentar el estigma y superar la descalificación y subalternidad, han seguido la consigna "el indio es bello". La identidad contrastada que busca delimitarse socioculturalmente selecciona determinados elementos entre otros posibles:

...la identidad nativa siempre resguardó la geografía entendida como la Pachamama (madre tierra de la cual procede la vida). La simbología cósmica permite el apego a la identidad del espacio y tiempo, inclusive en la ciudad. Se mantienen los rituales de educación, protección, ayuda y consentimiento. Los Q'aras solo habitan en el área urbana y ejercen un control estatal, sin embargo, los aymaras aprovechan los enclaves fronterizos, en transacciones comerciales e intercambio, aprovechan las ventajas de la oferta y demanda, evadiendo muchas veces el control estatal, que coarta el intercambio y la complementariedad (Chipana 1986: 254).

La distinción que hace la población indígena del altiplano de Iquique respecto del Q'ara, puede hallarse en las actitudes, opiniones y percepciones respecto de su forma de vida: es despilfarrador (no ahorra), es irrepestuoso con el buen comportamiento del ser humano, es débil para enfrentar el clima y las exigencias del medio ambiente de la región. Cuando se habla del buen o mal comportamiento se refieren a no seguir su propio sistema normativo. Así, situaciones tales como la separación matrimonial, la falta de respeto por el marido o la esposa, por los valores asociados al ciclo vital, el valor al trabajo, de la reciprocidad, entre otros, pueden dar pie a la descalificación; lo que puede derivar en la designación de Anuq'ara o perro, como opuesto a Jaqi, que quiere decir persona, estatus que se adquiere con el matrimonio.

El dirigente citado más arriba y hoy actual funcionario de Estado en la repartición estatal encargada de asuntos indígenas, caracterizaba al indígena regional de la siguiente manera:

Los aymaras con esfuerzo se han integrado al mercado de la libre competencia, mantienen una estricta política de austeridad en las unidades de producción, se capitaliza y reinvierte en bienes en forma ascendente, su nivel de consumo tiene una constancia, no cae con facilidad en el consumismo, por su condición de andino no es dado a adquirir bienes suntuarios, sino bienes de producción, también es muy autónomo como persona, no resiste la dependencia, es recíproco, pues nada puede dar en forma gratuita, todo debe ser reciprocado. Generalmente el aymara es muy buen comerciante, domina las técnicas del regateo, reinversión y ahorro. 
Cuentan siempre con capital mínimo propio, lo que les facilita aprovechar la oferta y están siempre atentos a las oportunidades, nunca se quedan sentados sobre sus éxitos. Persiste la concepción de la educación andina. Las normativas y valores ancestrales que los diferencian nítidamente del sureño (op. cit: 255).

Hoy la población de origen indígena es una población heterogénea en términos de clase y género, pero también en términos del grado de aculturación. A fin de exponer estas gradaciones consideraremos testimonios de mujeres y hombres que ilustran la relación pasado-presente que los mismos establecen. Dos de los primeros, un hombre mayor de Cariquima y una mujer joven de Isluga, residentes principalmente en el área rural, podrían representar a aquellos sujetos que a partir de la historia oral reflexionan sobre el pasado, argumentan su pertenencia y delimitan las fronteras culturales a partir de la historia local. El grado de aculturación menor, si lo comparamos con quienes han tenido mayor grado de escolarización y experiencia urbana, les lleva a no cuestionar las enseñanzas de las generaciones anteriores. El siguiente testimonio corresponde a un dirigente aymara de Cariquima de edad media con una fuerte experiencia urbana. Toma distancia para situarse frente a un relato que puede ser y no ser cierto. Ese pasado, antiguo, en el cual creció, es diferente al presente en la medida en que la modernidad lo cuestionaría. En consecuencia, expresa sentimientos ambivalentes. Luego veremos la reconstrucción histórica que hace un profesional aymara que busca apropiarse de la información que entrega la historia oficial para subvertir el orden político de la etnicidad y la cultura. Finalmente, aparece la reflexión de una mujer urbana cuya madre era de origen indígena y con un padre de la zona sur que se identificaba como "chileno". Esta última expresa las tensiones de dos culturas en un contexto en el cual los atributos del "indio" la llevan a experimentar la discriminación en la escuela. La distancia cultural se va produciendo a través de la socialización escolar y por su inserción en los barrios populares. Aunque formar parte del grupo de parientes por el lado materno le provoca acercamiento afectivo, no releva la identidad étnica en su práctica social y política.

Veamos el primer caso. En una conversación acerca de la religiosidad de los aymara, un abuelo relata, de un modo enfático y en un castellano aymarizado, a su sobrina:

Otro no pu', otra forma, wilancha ${ }^{10}$, ese de Inca; este la misa cualquier compadre, comadres, esa es otra cosa. Ese no pu', está la virgen no más. Ese no pu, evangélico dice el diablo, puro malo, diablo. $-\mathrm{No}$, no es diablo, porque diablo

${ }^{10}$ Término aymara que designa el sacrificio de un animal en la ceremonia ritual de ofrenda a las divinidades. 
es inocente, porque diablo es otra forma, es otro-. Porque el llamo dice, no? el llamo no se formó del dios ni padre, es Inca, como nació el piedra, en cerro, el inca hace nacimiento nació del llamo. Eso claro, porque nació del inca, su nacimiento, ahí el señor le bendició ....todo levantó esta tierra, por eso tres mil años tiene que cumplir, ahí vamos a ver necesitado los vicios, ahora no, 2500 años, ejercito de salvación, yo les leí pero ahí dice ah.... Por eso hay que florear llamito, porque el dios que marcan por eso que florean, por el Pachamama, el Inka mallku, Inka t'allla está viendo ... el Inka hace el llamo, no la gente, el dios, no, eso es de Inca. Uno le encomienda, por eso challar, eso dicimos, esos otros dicen diablo, aviador, dicen diablo diablo diablo... No. Hay que dar bendición, esta tierra todo comimos, todas las plantas quinuas, papas, arroz todo comimos...

Inca, todo el cerro, su hijo se nació del piedra, por eso tenía el inca, por el español lo mataron esos, porque saben de esos tiene oro, metales tiene, de ahí lo mataron, el cuerpo, de ahí el Perú... ahora está manteniendo el Perú?... el inca, eso sabemos, es como un dios, que vale como un dios padre, el inca, por eso estamos viviendo pobres acá, así no antes, seríamos ricos mismo.

Los argumentos apuntan a reafirmar la no coincidencia con la iglesia evangélica ni católica respecto del momento en que se produciría un cambio brutal del mundo. Los antepasados habrían dicho que a los tres mil años vendrá otra edad, momento en que las deidades exigirán cuentas por el mal comportamiento de los humanos. Este mal comportamiento se mide por no recuperar "las costumbres", es decir, por no amar al Inka Mallku e Inka T'alla, figuras centrales del pasado indígena y que habrían dado origen al orden actual, interrumpido por los españoles (los q'ara) para apoderarse de sus riquezas, transformándolos en pobres.

Aquí aparecen varios elementos que permiten elaborar la identidad étnica referida al otro más distante en el espacio social que han ocupado a través de varios siglos. El pueblo ganadero vive gracias a su ganado (llamas y alpacas) que sólo es manejado por la población indígena y que existe gracias al Inca, quien nació de la piedra en el cerro. El ganado y las destrezas campesinas propias reafirman la convicción de sus orígenes incaicos. El Inca fue vencido y su cuerpo destrozado en tres partes, pero volverá a nacer para restaurar el orden perdido. El mito del retorno, aquel que representa al estado Inca como un cuerpo humano que renacerá, es interpretado por los abuelos en términos territoriales. La cabeza, correspondería al actual Perú, otra zona intermedia (Bolivia) y las piernas a la zona sur del altiplano chileno.

Veamos ahora lo que nos dice la mujer:

Cuando el Jesús no existía, no había gente., estaban todos convertidos en animales, cóndor, lagartos, zorros, cualquier animal, tantas señoritas dice que se habían enamorado, de por ahí Jesús había encontrado esa virgen María y de por ahí los enemigos le habían encarcelado, los lagartos estaban presos, se habían ido a los cerros para engañar a sus esposas. Después llego la palabra del señor, el padre 
anda engañando, dicen, debería andar enseñando la Biblia, no enseñando a tomar, a bailar así.

La memoria colectiva también incorpora un pasado en el que la humanidad se confundía con los animales, elementos que se recuperan para interpretar las nuevas enseñanzas de la iglesia evangélica pentecostal ${ }^{11}$. Los cuentos y leyendas nos muestran geosímbolos en los que se ancla esta memoria:

los abuelos siempre hablaron de Inca Mallku, Inca T'alla, el rey inca. El inca fueron los primeros hombres que vivieron en el sector hacia el sur del Perú y de ahí provino ya esa gente con todas sus creencias del Inca. Así que el Inca es el que respetaba todas esas creencias, Wilanchas adoraba al cerro en fin de ahí provino eso. Eso hablaron los abuelos así yo desperté así nací con esa historia que el inca formó esas costumbres.

Las montañas forman parte central de la mitología y son el lugar privilegiado para los rituales propiciatorios, son representadas como antepasados o achachilas. En la entrevista colectiva que se presenta a continuación vemos como son percibidas de acuerdo a atributos que van configurando una identidad emblemática:

Mujer: Por ejemplo acá en Kiñuta decían Sojay Mallko, Escarwaya T'alla. Hay dos cerritos pues, de Wanka al frente hay cerro más abajo hay un cerro pal lao de Kiñuta,

Hombre: Si tu miras ese cerro tiene cara de gente pue, Escarwaya. Ud. le miras de Kiñita, es un hombre excelente,

Mujer: Wanapa también ese norte, tiene brazo codo, pata, para delante cara mismo con su arito, cara larguito, cara de india, larguito,

Mujer: ahí, así es pues

Hombre: Cara de Inca...

Mujer: $\quad$ Claro Inca son esos pues, antes andaban en sus cerros, ese Wanapa ha venido de allá, de Bolivia ha venido dice pues. Por eso dice que estaba enamorado de los cerros de Sabaya de Cawaruraya

Hombre: Incluso el Wanapa de otro Sabaya...

Mujer: Le echaron con sartenejo el Sajama. Después El Sabaya se enamoró, después Wanapa se arrancó, dice que estaba siguiendo, de ahí hondeó. Wanapa le hondeó. Esos cerritos chicos son los hijos de Wanapa. Con dos guaguas ha venido Wanapa, Wanapa chico, el otro está allá al otro lado donde esta pina pue, con ese dos hijos.

Mujer: $\quad$ Ese se vino siguiendo al Sillajuaya

Mujer: $\quad$ No, Wanapa es muy jodío por eso se arrancó pu, y se fue a la pampa

Mujer: ¿Su marido es Sillajuaya?

${ }^{11}$ En 1989, cuando la Iglesia Evangélica Pentecostal se expandía en las comunidades altiplánicas, las mujeres solían buscar los mitos de orígenes en la Biblia. Cuando no hallaban nada en ella, sorprendidas insistían en que la omisión se debía a una mala lectura de ellas. 
Mujer: $\quad$ No sabemos, Sillajuaya será pues

F: $\quad$ Sillajuaya ..., cuento de abuelo

Hombre: Por eso hablaba que antiguamente el zorro se convertía de día gente, de noche es zorro, lagarto igual,

Mujer: en la noche se convertía en gente, al revés

A partir de estos antecedentes es posible entender cómo un joven profesional aymara también recupera al Inca para apropiarse de la historia oficial y, desde allí, desplazar el estigma:

Históricamente la población aymara es parte de la civilización andina, que ha atravesado diferente estadios culturales. Los desarrollos locales y regionales convergen a través del tiempo hasta conformar la federación de los pueblos del Tawantinsuyu, estado políticamente dividido en cuatro suyus y gobernados por autoridades representativas. El ayllu, grupo de unidades domésticas, era la unidad orgánica básica de las sociedades aymara y quechua que conformaba el Tawantinsuyu. Cada ayllu propendía a la autosuficiencia de las familias, la reciprocidad comunal, la reproducción social, armonía con el medio ambiente, etc.... La población andina en sus respectivas repúblicas fue llamada y obligada a sostener la lealtad patria, en desmedro de su identidad, si bien en la colonia, explícitamente eran indios en las nuevas repúblicas adquieren la condición de ciudadanos con igualdad de derechos, igualdad que en los hechos no se dio. Los aymaras nortinos en la nueva jurisdicción fueron sometidos a una política de dominación cultural... (Chipana 1986:252 3).

En el otro extremo, hallamos un segmento de la población descendiente que, a pesar de tener raíces filiales, no se identifica étnicamente, pero sí racialmente y cultiva lazos afectivos con los parientes maternos. Rosa, nos dice:

... mi mamá hablaba en aymara y en quechua pero como te digo yo nunca le entendí. Mi papá no dejó que nosotros habláramos. Según él éramos chilenos, no bolivianos. Mi experiencia en la escuela fue pésima porque mi mamá tenía la manía de hacernos moños (trenzas), pero un moño acá y dos acá ... odio el pelo largo, honestamente lo odio. Se burlaban, se reían, te tiran el moño de arriba y vergüenza más que nada. No me gustó el colegio porque pasé mucha vergüenza, andar con los vestidos largo, el uniforme hasta abajo, las medias hasta arriba que no se te vea nada, que te digan indita, paisana cosas así, ¡córrete de acá indiai, ¡sale paisanai

El otro día vino un tío lejano, que es primo hermano de mi mamá, a buscarnos para que conociéremos su pueblo, Chapiquiña, que nosotros éramos sangre de ellos. Fuimos pa'l mes de las cruces, es una fiesta religiosa donde se hacen las guatias, donde se hace un hoyo en la tierra, porque cuidan mucho la Pachamama, entonces, hacen un hoyo y echan piedras, la van como sellando con piedras. Echan todo adentro lo que es la carne en una olla, chanta las ollas, las humitas, las papas crudas, con hollejo todo, el choclo, el camote y todo eso después se tapa y se pone pasto arriba, después unos sacos. En veinte minutos esta listo, pero como te dijera, se trabaja todo acelerado. Yo no tenía idea que eso era la Guatia. 
Con mi tío hemos ido a la fiesta de San Andrés de Pachama, hemos viajado y es precioso. Son unas fiestas religiosas que se baila, incluso mi tío como pertenece a él yo te digo honestamente yo bailo porque me gusta no es porque sea fanática en lo religioso sino me gusta porque me relajo. Otra fiesta son los carnavales. Andaban las niñas bailando Wayño, vestidas de Wayño y delante de ellas anda un hombre vestido de mujer, pero así bien ancha. La mujer así con hartas cosas, así de polleras y el hombre con una máscara de demonio. Eso me asustó mucho a mí, fijate de demonio. Pelo largo, con unas cosas así marcas y con una huasquilla (lazo trenzado). Si tú te acercas al hombre, bailando así la mujer te pega, es la tradición. No sé porque será así. Si un hombre se acerca a la mujer, el hombre te castiga con esos látigos, en las piernas y tú sales arrancando, entonces esas cosas a mí me dio miedo. Pero es que es una tradición de ellos. Una que es turista no la conoce.

Mira mis hijos ellos dicen que no están ni ahí con el interior. No se sienten del interior, porque ellos nacieron aquí en Arica y dicen tu tení sangre, nosotros no. Pero la sangre les tira porque mi hija es buena para bailar wayño ha bailado en el colegio, ha participado han ganado premios en el curso de ella porque han bailado los bailes nortinos así que me siento orgullosa de eso.

El testimonio de Rosa puede representar uno de los múltiples casos de "fuga étnica", es decir, casos en los que a pesar de recibir una socialización mixta, vinculada a la cultura indígena, termina distanciándose de la misma y releva otras identidades. Sin embargo, observamos a una gran mayoría de personas que, a pesar de esta distancia, adopta la identidad étnica aymara:

mira, nosotros tenemos muchos símbolos, que son nuestros espíritus como por ejemplo el cóndor, que son animales sagrados, la hoja de coca que sirve para los ritos, tenemos los cerros grandes tutelares que son hombre y mujer. Siempre en la cosmovisión andina aymara esta la dualidad, siempre esta hombre y mujer, la pareja chacha-warmi, están los cerros, tata Inti el sol, la Pachamama, sin ellos no puede haber un equilibrio, cuando el espíritu del ser humano está tranquilo, no hay una separación entre el cuerpo y el alma ahí está la dualidad, pero cuando falta uno de ellos, el cuerpo empieza a cojear, y es ahí donde estamos nosotros los guías espirituales, chamanes [...] para poder ordenar, ¿no sé si hoy día ustedes vieron La Estrella? en donde sale un reportaje de mí, a ver si la consiguen. Tenemos muchas cosas como la apacheta que hoy estamos challando estamos esperando no más antes de las 12 para cambiar el Wiphala por el Collasuyu, que es la bandera blanca que nos representa, hay muchas cosas como el agua el amaru, y para nosotros se pueden llamar símbolos de nuestros ancestros, como los petroglifos que ellos lo dejaron muy marcados en los cerros.

A diferencia de las referencias anteriores, esta última traspasa el tiempo Inca para identificarse con las poblaciones anteriores; aspecto que no está presente en la población altiplánica con menor grado de aculturación. Sin embargo, la selección azarosa de elementos culturales que menciona como símbolos habla de un proyecto utópico que es útil para reivindicar 
su condición social en la nación y posicionarse frente al Estado y a una sociedad discriminatoria. Como a muchas otras personas residentes urbanas, esta adscripción le sirve para ser protagonista social y político en una sociedad que ha relegado al indio al último lugar en la escala social y de un Estado que hoy asume la etnicidad como una variable, entre otras, para disminuir los cada vez más altos porcentajes de pobres que aún existen. Parafraseando a Goffman (2003: 48):

\begin{abstract}
Los que en un momento tardío de la vida advierten que han sido siempre personas desacreditables, reorganizan su visión del pasado; ejemplifican una tercera pauta de socialización. Son individuos que han realizado un concienzudo aprendizaje de lo normal y lo estigmatizado mucho tiempo antes de tener que considerarse a sí mismos como personas étnicamente diferente. Es probable que tengan un problema especial en re-identificarse consigo mismos, y una especial facilidad para la auto censura.
\end{abstract}

Si el "otro" más distante en el espacio de interacción cotidiana es el Q'ara, ¿Existen distinciones étnicas al interior de la población indígena?, ¿Podríamos llamar identidad étnica a las identidades locales?

\title{
DISTINCIONES ÉTNICAS INTERNAS DE LA POBLACIÓN INDÍGENA
}

Hace ya tiempo que entre los estudiosos de los Andes se sabe que lo que se denomina como tradición andina puede ser considerada como un tronco cultural común a pueblos con variedades lingüísticas y que constituían un gran número de grupos étnicos:

Destacan en nuestro territorio los aymaraes y los atacameños, dentro de los cuales también sería necesario aceptar matices y desarrollos diferenciados dentro de sus respectivas matrices. A esto debe agregarse el mayor o menor grado de aculturación que en algunos casos ha pasado a ser lisa y llanamente asimilación (Hidalgo 2004: 645-246).

A diferencia de Bolivia, donde, al parecer, los nombres propios de los diferentes grupos persisten (Pakajes, Machas, Karankas, Chichas, etc.) en los pueblos del lado chileno se autodenominan como Isluga, Cariquima, Chiapa, nombre que reciben las comunidades históricas formadas a fines del siglo XVIII. J. Luis Martínez (1997) nos dice que cada uno de estos grupos se distingue por el uso de trajes específicos en los que la combinación de colores y formas son básicas. Gundermann (2001) ha proporcionado elementos contundentes para señalar que la comunidad indígena en la región es producto de las múltiples coyunturas históricas coloniales. El ordenamiento socio territorial se habría organizado de acuerdo a un esquema normativo y socio simbólico particular. Este se habría aplicado 
como respuesta a las exigencias impuestas por el sistema político y económico imperante, aumento demográfico, etc. De esta tesis se infiere que la identidad localista que hallamos hoy se vincularía con estos procesos:

Un campesino aymara en el siglo XVIII era simultáneamente tributario, comunero y feligrés; i.e. miembro de un sistema administrativo y político, de la comunidad y de una iglesia. Los arreglos específicos que determinan finalmente la pertenencia en este contexto se organizan en torno a la estructura social dual, característica de los poblados andinos: mitad de arriba y abajo (Araj Saya/Manqha Saya) (ibidem).

Si la comunidad que hoy observamos se formó a partir de diferentes contingentes de población y con arreglo a las exigencias socioeconómicas y sociopolíticas, la pregunta que resta es cómo se fue configurando esta identidad localista. Es decir con arreglo a qué argumentos. Hoy podemos rastrear elementos que los miembros de estas localidades elaboran para distinguirse entre ellos mismos y que muchas veces no son necesariamente observables al q'ara. Los comuneros de Isluga dicen que ellos son diferentes de los de Cariquima porque descienden de antepasados distintos y provienen de otros territorios. La tradición textil es distinta y sus uywiris ${ }^{12}$ son otros. Las formas de realizar las ceremonias religiosas y la forma de hablar y vestirse serían también diferentes. En lo que se refiere al tejido, se menciona la falta de dedicación que deriva en no cuidar la técnica y la estética. A su vez, la gente de Cariquima menciona el apego a la tradición por parte de la de Isluga, por tanto sus textiles son más bellos y conservan las prácticas ceremoniales. Aunque esta distinción posee una connotación negativa porque se trataría de prácticas indias que entorpecen la integración a la sociedad nacional y la modernización. Tanto en Isluga como en Cariquima dicen que los de Chiapa, comunidad de valle, con un estilo de vida agrícola y no ganadera como ellos, no poseen conocimiento alguno sobre la vida en el altiplano (tejer y pastorear el ganado). Argumentan que el vestido de mujeres y hombres era particular. Efectivamente, en carnavales las mujeres usan Aksus negros largos, sin color ni dibujos, más ajustados y abiertos al lado derecho "a la usanza del inca". Los hombres usan un tipo de poncho listado y corto, parecido al estilo Chipaya. Sin embargo, Chiapa tiene la particularidad de ser un pueblo de larga tradición andina; es pueblo de gentiles, por tanto se debe respetar. Esto contrasta con su temprana modernización, dada su vinculación con las dinámicas que impulsó la industria del salitre. El reemplazo del vestido y la migración, ya sea por motivos educacionales o de trabajo, y

${ }^{12}$ Se trata de lugares sagrados en los cuales se realizan los rituales a los antepasados. Estos, justamente poseen nombres propios. 
la pérdida del uso de la lengua fueron algunas de sus consecuencias más importantes. Aunque las festividades religiosas se han transformado, persiste su forma particular de celebrarlas.

La gente del altiplano recuerda la forma de hablar de este valle, con un estilo propio y también una tradición textil propia. Esta visión es similar a la que poseen en las comunidades de Cariquima, Isluga y Sabaya respecto de los Chipayas, pueblo vecino del salar de Coipasa. Estos habrían sido los únicos que sobrevivieron a la época de la luna y la oscuridad. Los Chipayas son un pueblo que, según los aymara, vive de manera precaria y a la usanza antigua y su lengua es la que hablaban las poblaciones antiguas. Por este motivo se les debe respeto. Aparte de su lengua y estilo de vida (viviendas y prácticas productivas), se distinguen por su forma de caminar, sus vestimentas (cuando las usan), el modo de comer y el peinado de las mujeres ${ }^{13}$.

Aunque se reconoce la posibilidad de intercambios matrimoniales entre estos grupos, también se argumenta que, dadas las diferencias de estilos de vida, no es conveniente. Tanto las normas y valores como la experiencia en las actividades agrícolas-ganaderas y textiles son razones suficientes para evitarlos. Si bien la pertenencia a la iglesia evangélica pentecostal en el caso de terceras generaciones en la ciudad ha tendido a transgredir estas fronteras, persisten estas convicciones. Asimismo, las elecciones municipales son dirigidas por una competencia entre las comunidades.

Así como las personas de Isluga suelen llamar a sus vecinos del Coipasa como chipayitas, los Sabaya nombran a los primeros como isluguitas, en un sentido ambivalente: habitantes que mantienen las costumbres de los antepasados pero que no alcanzan los estándares modernos que exigen las nuevas formas de vivir. En cierto modo, se les ve con desprecio pues poseen todos los signos del estigma del indio.

Ha sido durante el siglo XX, como consecuencia del impacto del modelo exportador de salitre, cuando los valles se han distanciado más de los pueblos del altiplano:

En Chiapa, antes se hablaba aymara, ahora no se habla, Chiapa con estos sectores eran casi iguales, su raza, su manera de vivir, lo único que ellos vivieron más al valle, también influyó un poco de cambiar las oficinas salitreras y volvió con muchos cambios yo recuerdo muy bien que cuando nosotros bajábamos con llamos a comprar peras a los valles nos decían indios, paisanos y ellos se reconocían

${ }^{13}$ En los años ochenta, después de vivir un año ya podía poner en práctica estas distinciones en las ferias quincenales que se hacían en la frontera. Mientras las mujeres de Isluga tendían a peinarse con cuatro y ocho trenzas, las de Sabaya en dos sujetadas con adornos, las de Chipaya superaban las doce. Aprendí también a distinguir a las mujeres Chipayas solteras de las casadas. 
gente superior, entonces bueno aceptarlos ahí bajábamos con mulitos, murientitos con chalas con ojotas, ellos ya tenían zapatos ya entonces con tener zapatos y con saber hablar el castellano más o menos perfecto ya nos trataban como gente baja, me acuerdo que en mocha decían ahí llegó un paisanito un paisanito chiquitito, mira cargadito también el paisanito.

Asimismo, la gente del altiplano recuerda cómo los niños eran amonestados por ingresar en las escuelas rurales de los valles por su condición de "indios". Estas distinciones internas comienzan a visualizarse en la actualidad a propósito de conflictos en el interior de las organizaciones étnicas. A modo de hipótesis, es posible pensar que los recientes grupos quechuas emergentes, como otro grupo étnico regional, buscan distinguirse a partir de esta diferenciación:

Hoy en día nuestros pueblos andinos han ganado espacios en todo orden de cosas, especialmente a nivel político y administrativo. Sin embargo nuestra región, en su mayoría, ha reconocido una gran presencia aymara, pueblo que geográficamente perteneció al territorio cordillerano y altiplánico pero por los procesos de migración se han establecido en los valles y la ciudad buscando una mejor calidad de vida o bien para entregar estudios a sus hijos. Esta zona acoge también en su seno a una cultura no menos importante pero sí muy poco difundida en la región. Esta cultura corresponde a los hermanos quechuas, que de la misma forma que nuestros hermanos aymaras necesitamos mantener viva nuestra historia y vigente nuestras raíces.

Es por ello que necesitamos unirnos en la reconstrucción de nuestra identidad para dar a conocer nuestra fortaleza de pueblo. Que estamos acá, entre ustedes esperando que este Pachakuti renueve y preserve nuestra cultura quechua, porque somos parte de esta diversidad andina y herederos de un pasado histórico. Queremos promover una lucha de reivindicación entre nuestros hermanos andinos para nuestra cultura, queremos que nuestra palabra Pachamama de origen quechua sea escuchada y pronunciada también por nuestros llactamasis (hermanos), queremos finalmente elevar nuestra voz para reverdecer nuestro legado incaico y sobre la base de ello proyectar un futuro sustantivo, firme y seguro ${ }^{14}$.

Estos antecedentes sostienen que la identidad local es identidad étnica y que esta fue una estrategia de adaptación durante varios siglos para reafirmar sus pertenencias culturales pero sobre todo las territoriales. Por otra parte, dejar de ser indio por mucho tiempo ha sido una lucha por desembarazarse de un estigma, mas no de su condición étnica. El surgimiento de una identidad "panlocal" fue posible por la movilización de jóvenes urbanos escolarizados y otros actores no indígenas sobre la base de la experiencia histórica de discriminación negativa y de la memoria indígena que persiste en la diferencia. En otras palabras, el paradigma de

${ }^{14}$ Cartas al Director del Diario La Estrella de Iquique, martes 30 de septiembre de 2003. 
la etnicidad como herramienta política logra convocar a una población que recupera una memoria de adscripción a un pasado que le pertenece sólo a ella; pero en un momento histórico particular en América Latina y en el mundo. Cuando el reconocimiento por los pueblos indígenas ya había comenzado y cuando, en Chile, estudiantes universitarios se organizaron para reivindicar sus derechos étnicos, como sucedió durante la década de los ochenta.

La identidad emblemática, que se ha ido entrelazando con una identidad estratégica para acceder a determinados bienes, es planteada también en Bolivia. Álvaro García al hacer un análisis de coyuntura a mediados de 2001, titula su artículo: "Indios y q'aras: la reinvención de las fronteras internas". Propone que la fuerza del lenguaje y de la movilización indígena habría reconfigurado las fronteras de las representaciones de los grupos sociales legítimas al sustituir las antiguas divisiones discursivas dominantes: proletarios/burgueses, ciudadanos/ marginales; modernos/tradicionales, por otras indios/q'aras; aymara quechuas/mestizos (García 2001).

\section{REFLEXIONES FINALES}

Lo expuesto permite señalar que la cuestión étnica en la región debe continuar investigándose. Es preciso obtener antecedentes empíricos de los procesos que hoy se dan aquí, en relación a otros contextos sociohistóricos. Los procesos de modernización han afectado a la población indígena de modo particular. El sistema educativo ha impactado fuertemente en la población del país en general y en la de origen indígena ha implicado procesos de aculturación acelerados, lo que junto a los procesos de diferenciación social ha conducido a una heterogeneidad social, cultural y económica.

Los antecedentes más inmediatos en términos de procesos identitarios en contextos de cambios estructurales, nos sitúan en el siglo XIX. La nacionalidad como expresión de identidad impuesta por el Estado fue el modo de dominar a una población "extranjera" residente en el nuevo territorio y así extender el proyecto de nación. Para los aymara fue una estrategia para mantener los recursos productivos y de integración social en un sistema sociopolítico. Esta fue adoptada, en primer lugar, por las elites; es decir, por los grupos con mayor grado de aculturación, mientras que los sectores marginales fueron tardíamente involucrados.

En la década de 1980 los jóvenes universitarios lideran un proceso de lucha por el reconocimiento étnico, a partir de procesos que se dan en países vecinos, especialmente en Bolivia. La etnicidad, como paradigma identitario, fue adoptada por un sector de la población con mayor grado 
de integración y con mayores niveles de aculturación (residentes urbanos); situación que se fue expandiendo a toda la región con ayuda de ONGs y del Estado, a través de su política de afirmación positiva. Esta identidad étnica, que supera a la localidad para abarcar a toda la población de origen indígena, se sustenta en la frontera cultural que se ha construido a través de varios siglos y que se expresa en la división indio/q'ara. La identidad instrumental se apoya en una identidad emblemática o como símbolo. El pasado, aquello que legitima la pertenencia, se representa en el "Inca". Un espacio-tiempo mítico, un sistema normativo y de valores que otorga un esquema de percepción para orientar las prácticas; pero sobre todo define los límites étnicos. La pertenencia étnica "real", "asignada" y/o "adoptada" se torna más importante que el estatuto de clase, aunque objetivamente también formen parte de las clases subalternas.

En este sentido, podríamos decir que los procesos de modernización han llevado a una exaltación de la etnicidad; pues ella proporciona una herramienta política para reafirmar la diferencia cultural y demandar su reconocimiento; situación inédita en la historia. Si la modernidad actual ha producido un efecto pluralizador en las identidades, lo cierto es que las prácticas identitarias adquieren una relativa integración y coherencia por la acción de varios actores, tanto en el interior de la sociedad indígena como en su exterior. Entre los primeros podemos mencionar a la comunidad de parientes, yatiris y otros líderes. Entre los segundos al Estado, las Iglesias, los medios de comunicación y la sociedad civil no indígena, en cuanto que se han encargado de administrar la diferencia y su calificación.

La puesta en riesgo de la integridad de la comunidad cultural indígena ha sido frenada por múltiples estrategias. Una de ellas ha sido el tipo de relación que ella misma ha establecido con la sociedad regional. En términos socioeconómicos a través de la producción campesina y en una zona desértica y particular en el contexto del territorio nacional; dado el manejo del medio ambiente y las tecnologías apropiadas. Estas últimas forman parte de tradiciones que proveen los conocimientos necesarios cuya vinculación con la religiosidad, con el sistema normativo y de los valores es clave. Este background cultural ha persistido como respuesta al otro ( $q^{\prime}$ ara) con el cual convive cotidianamente. Es posible enunciar dos mecanismos en esta estrategia. Primero, hacer todo aquello que el otro prohibe o no le gusta, de manera reservada. Segundo, manejar la relación con el otro de acuerdo a un principio de desconfianza. Eso no implica no haber adoptado múltiples prácticas que se consideran ajenas, "occidentales" como suelen llamarlas los dirigentes. La resolución de la vida cotidiana (alimentación, vestido, salud) ha implicado acudir a la tradición y 
adecuarla a las nuevas condiciones contextuales. Gran parte de estas prácticas son para el q'ara signos de incivilización, por lo tanto fueron ocultadas o simplemente evitaron ser vistas.

El sentimiento de desconfianza del q'ara se expresa en una reacción de alerta. Negarse a sí mismos y negar al otro tal vez implica contener este sentimiento sin nombrarlo, pero que se manifiesta permanentemente en la interacción. La clasificación del otro en la expresión q'ara no conlleva el sentido humano del término Jaqui. Etnocentrismo, en el sentido literal del término, que si bien promueve la identidad y articula un movimiento, dificulta las posibilidades de establecer estrategias de alianza. Pero, el largo período de represión política que vivió el país, el volumen de población en relación a la población total y la ausencia de su participación en las luchas políticas que se dieron en la región, a diferencia de Bolivia y Ecuador, por ejemplo, han impedido la reflexión histórica y política para elaborar un proyecto propio en la modernidad.

Los argumentos para establecer las fronteras étnicas sirven hoy para desechar el estigma y afirmar su identidad étnica e iniciar procesos de acción colectiva dirigida a luchar contra la hegemonía cultural. Sin embargo, no existe una estrategia política consciente para cuestionar al Estado-nación en su proyecto cultural, socio-económico o sociopolítico. La poca experiencia en participación política de los dirigentes y de la población de origen indígena del norte chileno en general, es un signo de la escasa integración a la comunidad política.

\section{BIBLIOGRAFÍA CITADA}

CERECEDA, V. 1978. "Semiologie des tissus Andins: Les talegas d'Isluga”. Annales 33 (56): $1017-1035$.

Chipana, CoRnelio. 1986. "La identidad étnica de los aymarás en Arica». Chungará 16/ 17: 251-261 Universidad de Tarapacá, Arica, Chile.

D'ANDREA, Dimitri. 2000. “Las razones de la etnicidad entre globalización y eclipse de la política", en Furio Cerutti y Dimitri D'Andrea (eds.), Identità e conflitti: 83-91. Milán: Franco Angeli.

GARCíA, ÁlVARO. 2001. "Indios y q'aras: la reinvención de las fronteras internas". Debates, Observatorio Social de América Latina. http://osal.clacso.org/espanol/html/ fdebates.html.

GimÉNEZ, GilBerTo. 1994. "Comunidades Primordiales y modernización en México, en G. Jiménez y R. Pozas (coords.), Modernización e identidades: 151-183. México: Instituto de Investigaciones Sociales: Universidad Nacional Autónoma de México.

- 2000 "Etnia, Estado de la Cuestión", en Leticia Reyna (coord.), Los retos de la Etnicidad en los Estados-nación del siglo XXI: 45-70. México: CIESAS.

GoffMAN, ERVING. 2003. Estigma. La identidad deteriorada. Buenos Aires: Amorrortu Editores. 
GONZÁlEZ, HÉctor. 1997. "Apuntes sobre el tema de la identidad cultural en la región de Tarapacán. Estudios Atacameños:13-20.

-. 2000. "Identidad cultural aymara, nacionalidad y globalización", en S. Micco y E. Saffirio (eds.), ¿Hay patria que defender?: 283-286. Santiago de Chile: Centro de Estudios para el Desarrollo.

- y Vivian GaVilán. 1992. "Cultura e Identidad Aymara en el Norte de Chile». Chungara 24/25:143-158.

GREBE, MARÍA ESTHER. 1986. “Migración, identidad y cultura aymará: Puntos de Vista del Actor». Chungará 16/17: 251-261.

Guerrero, Bernardo. 1994. A Dios Rogando... Department of Cultural Anthropology/ Sociology of Development Vrije Universiteit, Amsterdam.

GundERMANN, HANS. 2001a. Comunidad sociedad andina y procesos sociobistóricos en el norte de Chile.Tesis para obtener el grado de Doctor en Ciencias Sociales con Especialidad en Sociología El Colegio de México.

- 2001b "Comunidad Aymara. Proceso de Cambio Social" Ponencia presentada en el IV congreso de Antropología, Santiago Chile.

Hidalgo, Jorge. 2004. Historia Andina. Santiago de Chile: Editorial Universitaria.

KESEEL, JUAN. 1991. "Los aymara contemporáneos de Chile (1879-1990) su historial social”. Dialogo Andino 10: 48-73.

—. 1996. "Los aymaras contemporáneos de Chile, en J. Hidalgo, en V. Schiappacasse, H. Niemeyer, C. Aldunate y P. Mege (eds.), Cultura de Chile. Volumen segundo. Etnografía. Sociedades indígenas contemporáneas y su ideologia: 47-68. Santiago de Chile: Editorial Andrés Bello.

Maluenda, Marcela y Paulina Valenzuela. 2004. Simbolos y ceremonias aymaras en las relaciones con el Estado. Tesis para optar al grado de Licenciatura en Sociología. Universidad Arturo Prat, Iquique.

MARTÍNEZ, GABRIEL. 1990. "El sistema de los Uywiris en Isluga", en Espacio y pensamiento. I. La Paz: Hisbol.

-. 2001. "Saxra (diablo) Pachamama, Música, Tejido, Calendario e Identidad entre los Jalq'a", Estudios Atacameños 21: 133-152.

MARTíNEZ, JoSÉ LuIS 1992. "Luces y colores del tiempo aymara". Boletín del Museo chileno de Arte Precolombino 1: 27-40.

OOMmEN T. K. 1994. "Raza, etnicidad y clase: análisis de las interrelaciones". Revista Internacional de Ciencias sociales 1, 39: 101-113.

TUDELA, PATRICIO. 1992. Transformación religiosa y desintegración de la comunidad aymara tradicional en el norte de Chile. Bonn: Holos. 